\title{
LAS REFORMAS AGRARIAS EN MÉXICO Y LOS PROYECTOS DE DESARROLLO RURAL EN UN MUNICIPIO DEL ESTADO DE VERACRUZ ${ }^{1}$
}

\author{
Ana Isabel Cárcar Irujo \\ Universidad Pública de Navarra
}

http://dx.doi.org/10.5209/rev_NOMA.2013.v38.42917

\begin{abstract}
Resumen.- Durante el siglo XX México ha realizado dos reformas agrarias con el objetivo fundamental de intensificar las políticas de corte capitalista o neoliberal. La primera reforma consistió en la expropiación de tierras a los hacendados y su entrega a los campesinos creando los ejidos. Pero el Estado, tuteló todos los asuntos relativos a los mismos, manteniendo el control político y económico sobre el campesinado. Con la segunda reforma agraria aprobada en 1992 se permite la privatización de la tierra y desaparece la injerencia del Estado en las comunidades. Ambas reformas no pretendían una redistribución equitativa de la tierra, ni una mejora socioeconómica del campesinado, por lo que las consecuencias han sido similares en las dos reformas: el acceso a la tierra y a los proyectos de gobierno para el desarrollo rural continúa directamente vinculado a las relaciones de parentesco y al clientelismo político. No obstante, en la segunda reforma agraria es destacable la concentración de la tierra en manos de multinacionales. Los proyectos de desarrollo rural de la SAGARPA son analizados cuantitativa y cualitativamente en el municipio de Emiliano Zapata, Estado de Veracruz, para averiguar su relación con las redes clientelares.
\end{abstract}

Palabras clave.- reforma agraria, acceso a la tierra, proyectos, desarrollo rural

Abstract.- Throughout twentieth century, Mexico carried out two agrarian reforms with the fundamental lens to intensify the capitalist or neoliberal policies. The objective of the first reform was the expropriation of land to the landowners and his delivery to the country people creating the "ejidos". But the State supervised undertaken all affairs, maintaining political and economic control over the peasants. With the second agrarian reform approved in 1992, the privatization of the land is allowed and eliminates the interference of the State in the communities. Both reforms were claiming neither an equitable redistribution of the land, nor a socioeconomic improvement of the peasantry, for what the consequences have been similar in both reforms: the access to the land and to the projects of government for the rural development continues directly linked to the relations of kinship and political dependence. However, in the second reform the concentration of land in the hands of multinational companies is remarkable. The projects of rural development of the SAGARPA are analyzed quantitatively and qualitatively in Emiliano Zapata's municipality, State of Veracruz, to verify its relation with the patronage networks.

Keywords.- land reform, access to land, projects, rural development

\section{Introducción}

El presenta artículo analiza el acceso a los proyectos de desarrollo rural. Se pretende demostrar que los proyectos de gobierno contribuyen a la reproducción social, favoreciendo a las personas con recursos y excluyendo a los más necesitados. Para ello, se repasa la trayectoria histórica de la tenencia

\footnotetext{
${ }^{1}$ Doctora en Antropología Social y Cultural (Universidad Pública de Navarra).
} 
de la tierra desde la Revolución mexicana y se observa que las dos reformas agrarias han contribuido igualmente a la naturalización de la desigualdad. El clientelismo político, vinculado en ocasiones a las relaciones de parentesco, y el control estatal son dos factores añadidos. Los proyectos son analizados desde una perspectiva cuantitativa mediante los datos obtenidos de la SAGARPA, y cotejados cualitativamente con el trabajo de campo realizado durante diez meses en los años 2010 y 2011 en una comunidad campesina del municipio de Emiliano Zapata ${ }^{2}$, en el Estado de Veracruz.
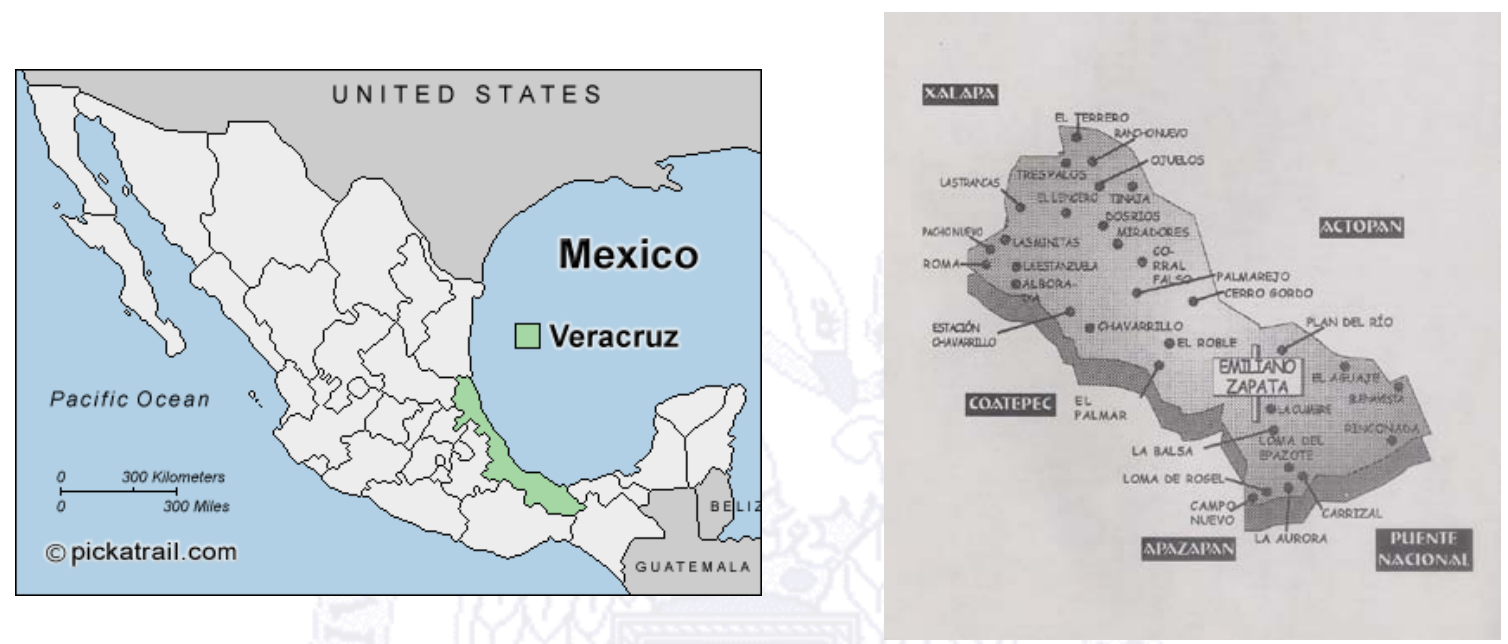

\section{Consecuencias del tipo de tenencia de la tierra desde la Revolución Mexicana hasta la Reforma Agraria de 1992}

En el siglo XIX se inicia la revuelta agraria en México, coincidiendo con la crisis económica mundial. Los primeros disturbios tienen lugar especialmente en las zonas en la que las haciendas acaparaban cada vez más tierra, con el objetivo de expandirse en los mercados internacionales (Torres Mejía, 1993). Con los enfrentamientos armados sucedidos durante la Revolución mexicana, entre 1910 y 1917, se abre un nuevo espacio de negociación política y se logra acabar con la estructura de dominación (Arizpe, 1993).

Tras varios siglos de arraigo habían salido de sus tierras a combatir los campesinos, los vaqueros, los jornaleros, los obreros y la clase media urbana, las soldaderas y los hacendados. Fue un movimiento repentino, "la bola", como decían, que se los llevó y creó un nuevo país: rompió las fronteras raciales, conservó la independencia y la integridad territorial nacionales, reivindicó un pasado indio y un futuro mestizo, y logró aglutinar a un mosaico de grupos regionales culturales, étnicos, inmigrados, y de clases emergentes, bajo las banderas de nacionalidad, justicia social, educación y democracia. Una vez

\footnotetext{
${ }^{2}$ Especialmente se realizó trabajo de campo en una comunidad campesina, cuyo nombre se omite debido a la necesidad de presentar en este trabajo algunos diagramas de parentesco, respetando de este modo la confidencialidad de los informantes respecto a los datos aportados sobre proyectos individuales y colectivos.
} 
consolidado $-\mathrm{y}$ negociado en silencio con los caciques regionales, Estados Unidos y la Iglesia- el nuevo régimen, los remolinos de gente se fueron a sus casas, otra vez en los parajes del campo (Arizpe, 1993: 377-378).

La particular situación socio-económica del centro y norte de México marca las diferencias entre Emiliano Zapata, cuyo objetivo principal es el reparto o restitución de tierras a campesinos y comunidades, y Francisco Villa, el cual no realizó ninguna reforma agraria en los territorios ganados (Tejera Gaona, 1993), pero ni Emiliano Zapata ni Pancho Villa reclamaban ejidos, sino tierras en propiedad (Morett Sánchez, 2008). Para Womack (2008) los campesinos mexicanos hicieron una revolución para no cambiar, lo único que deseaban era permanecer en sus pueblos y aldeas trabajando la tierra de sus padres y sus antepasados.

La reforma agraria se divide en dos etapas. La primera de ellas comprende los años de 1912 a 1934, y se caracteriza por la falta de reformas estructurales en la tenencia de la tierra. El segundo periodo se enmarca dentro de la presidencia de Cárdenas, de 1934 a 1940, cuando se distribuyeron 18 millones de hectáreas, con una verdadera transformación en la estructura rural. Durante los años treinta, en el primer periodo, México seguía siendo uno de los países con mayor índice de concentración de la propiedad de la tierra, el 83,5\% de la superficie correspondía a propiedades de más de 1.000 hectáreas y al mismo tiempo había 2,5 millones de campesinos sin acceso a ella. La oligarquía terrateniente había perdido el control sobre el poder estatal con la Revolución, pero continuaba influyendo significativamente en él, oponiendo resistencia política y militarmente al reparto. Además contaba con el apoyo del clero que intervenía para que los campesinos no aceptaran las tierras o no lucharan por ellas (Morett Sánchez, 2008).

La Hacienda El Lencero, fundada en el siglo XVI y situada en el municipio de Emiliano Zapata, constituye un buen ejemplo de esta situación. A finales del siglo XIX el General Santa Anna, propietario en ese momento, vendió 903 hectáreas a los hermanos Contreras, los cuales fundaron la hacienda Tepeapulco Nevería, a partir de la cual, y con las expropiaciones de la reforma agraria, surgirá en 1930 la localidad de Chavarrillo. Posteriormente, con la Revolución de 1910 la hacienda de El Lencero se vio sometida a continuos saqueos por grupos de "carranzistas", "villistas" y "zapatistas", que se apoderaron de la mayor parte de la producción, especialmente entre los años 1914 y 1918 durante los cuales varias actividades económicas fueron abandonadas definitivamente (Sánchez Gómez, 1979). Aboites ofrece un panorama general de la región:

La revolución acabó con el ganado de las haciendas, obligó a algunos a enrolarse en las filas del general zapatista Ricardo Morales, pero no transformó sustancialmente nada: los hacendados conservaron sus propiedades, los acopiadores de café su papel comercial, los peones y trabajadores sus empleos, sus tierras arrendadas, y los comerciantes sus tiendas (Aboites, 1980: 9).

Pero a partir de 1923 comenzaron las expropiaciones de la hacienda El Lencero, conocidas como las afectaciones agrarias, siendo la primera reducción de 600 hectáreas que pasaron a ser propiedad del poblado de El Chico. El proceso de Reforma Agraria se completó en 1939, momento en el 
cual se produce la mayor expropiación: 3.025 hectáreas. La hacienda quedó reducida a 292 hectáreas aproximadamente. El siguiente mapa muestra cómo quedó fraccionado El Lencero a partir de 1939. Las letras A, B y C identifican a los tres terrenos que el propietario del momento conservó (Sánchez Gómez, 1979).

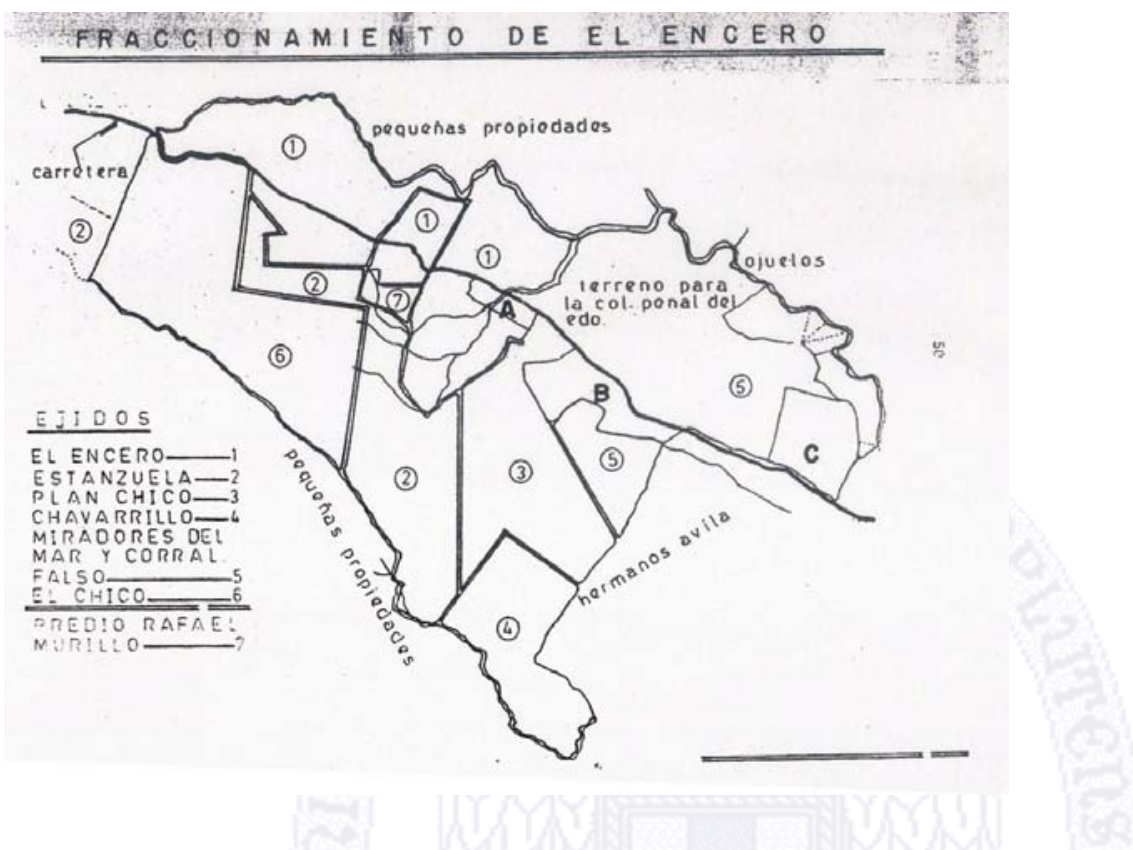

La situación a principios del siglo XX en torno a la hacienda de El Lencero se repetía por todo el estado de Veracruz. Romana Falcón muestra la desigual distribución de la tierra en esta época:

De esta manera se calcula que en 1910 existían en el estado 536 haciendas, con un total de 2.672.959 hectáreas, pero sólo siete de ellas poseían el $20 \%$ de esta superficie, mientras que el $30 \%$ de las propiedades privadas, cuyas superficies fluctuaban entre las 100 y 1.000 hectáreas, no llegaban a cubrir ni el tres por ciento de la superficie usufructuada por particulares. Por otro lado, más del 95\% de los trabajadores rurales carecían de tierras (Romana Falcón, 1977: 28, 29. Citado en Sánchez Gómez, 1979: 52).

No obstante, el único objetivo del reparto agrario antes de la presidencia de Lázaro Cárdenas residía en evitar las revueltas, por lo que fue insignificante. Pero en el periodo de Cárdenas, además de controlar los movimientos campesinos se intenta eliminar la oligarquía terrateniente por dos razones. La primera de tipo económico, debido al control de precios que imponía el monopolio de las haciendas, que encarecía los salarios y las materias primas ${ }^{3}$. En segundo lugar el nuevo modelo capitalista requería de una modernización del campo con una fuerza de trabajo libre, debido a que los peones que sostenían la hacienda suponían un lastre para el capitalismo agrario (Morett Sánchez, 2008).

\footnotetext{
${ }^{3}$ La industrialización de México de los años treinta no era compatible con un sector agropecuario que imponía sobreprecio a los productos.
} 
En principio se esperaba que el trabajo principal no se desarrollara en el ejido, por lo que la dotación se concede para complementar las actividades de los campesinos. Sin embargo, esta modalidad se modificó hasta suponer que de la parcela ejidal el campesino obtendría la producción suficiente para satisfacer sus necesidades materiales e intelectuales. La tierra se entregó en usufructo porque al ser el sector ejidal la clase económicamente más débil podrían perder las parcelas por endeudamiento y así reconstruirse el latifundismo (Cárdenas, 1968). Por otro lado, la propiedad privada y la comunal no se consideraron excluyentes, sin embargo, se favoreció notablemente a la primera, de tal forma que la legislación de la reforma agraria define a la pequeña propiedad como un predio veinticinco veces mayor que a la parcela ejidal (Stavenhagen, 1968). De esta forma el ejido y la pequeña propiedad se constituyeron como la nueva estructura agraria de México.

Con todo, la extensión promedio de los ejidos durante el cardenismo fue de 4,5 hectáreas de temporal y 1,2 de riego, terreno insuficiente para subsistir. Si el objetivo de la Reforma Agraria hubiera sido crear granjas familiares el reparto de tierra laborable habría sido mayor, también se habrían entregado herramientas y los medios de producción de las haciendas. Habría sido necesario crear un amplio sistema de crédito, puesto que a pesar de que se crea el Banco de Crédito Ejidal, éste se orienta fundamentalmente a los ejidos colectivos $^{4}$; y por último un sistema de comercialización para que el excedente campesino no acabara en manos de acaparadores. En 1925 se aprobó la Ley Reglamentaria Sobre Repartición de Tierras Ejidales y Constitución del Patrimonio Parcelario Ejidal en la que queda establecido el reglamento sobre el ejido, entendido como forma corporativa de tenencia de la tierra. Por primera vez se prohíbe el arrendamiento, las tierras se declaran inalienables e inembargables, los terrenos de agostadero y monte pasan a ser de uso común, las tierras de cultivo se parcelan y se trabajan de forma individual y los terrenos de uso común son para aprovechamiento comunal. En 1934, en el periodo de Cárdenas, se promulga el Código Agrario en el que se añaden dos nuevos elementos: el ejido adquiere carácter imprescriptible, es decir, se convierte en definitivo y permanente; y el Estado queda legitimado para intervenir de forma directa en todos los asuntos de la vida ejidal (Morett Sánchez, 2008).

El artículo 148 del Código Agrario autorizaba al gobierno a definir los cultivos, establecer las técnicas, la forma de organización de los ejidatarios, ya sea para la producción o para el comercio, el modo del aprovechamiento forestal, pecuario, magueyero o de cualquier otra clase de recurso con que contara el ejido y cualquier otro concepto social o económico importante para la comunidad (Morett Sánchez, 2008: 84).

El sistema ejidal fue la única forma de acceso a la tierra para los campesinos y la peculiar manera que el Estado encontró para acabar con las revueltas agrarias y controlar económica y políticamente a los trabajadores rurales. La prohibición de vender las parcelas impidió la reconstrucción de la oligarquía

\footnotetext{
${ }^{4}$ El Banco Ejidal (Banrural) actuaba con el ejido en su conjunto, considerándolo como una unidad productiva, pero también por medio de asociaciones o cooperativas. Por esta razón los ejidatarios no podían negociar los créditos individualmente. En el supuesto de que uno de los ejidatarios no cumpliera con el pago del préstamo el conjunto del ejido perdía el derecho a crédito. Esta situación respondía a la consideración de la tierra como propiedad social inembargable.
} 
terrateniente, pero también impuso un estricto modelo de organización a los campesinos, que quedaron subordinados al Estado y dependientes de los créditos del gobierno o de los usureros.

Por otro lado, el reparto de la tierra no fue acompañado de otras medidas necesarias para la modernización del agro, tales como el aumento de la productividad, la diversificación de los cultivos, el otorgamiento de créditos, la creación de proyectos de riego, la asistencia técnica o la organización de los campesinos (Cárdenas, 1968). Desde el punto de vista económico el ejidatario es un pequeño productor mercantil, que produce a pequeña escala con parcela de propiedad privada limitada, y que está inmerso en los mecanismos del mercado capitalista (Morett Sánchez, 2008).

Teniendo en cuenta las limitaciones que afrontaban los ejidatarios, el desamparo por parte de las instituciones gubernamentales y estatales y el fomento del caciquismo desde las mismas instituciones, parece poco probable que los ejidos se constituyeran como un modelo económico viable dentro del sistema capitalista con el que irremediablemente debía de articularse. A pesar de que varios ejidos, influenciados por la ideología socialista que imperaba en algunos países, cimentaron sus comunidades sobre relaciones de reciprocidad y redistribución, el nuevo sistema de tenencia de la tierra tenía como objetivo central intensificar un modelo de mercado capitalista que se contraía fundamentalmente por el poder de los hacendados en el control de precios, asunto que quedó resuelto en perjuicio de los nuevos campesinos. No obstante, este nuevo sistema no sólo implica cambios en la forma de tenencia de la tierra, sino también variaciones en la organización social que queda asentada sobre valores y principios cuyo origen proviene de la civilización Mesoamericana ${ }^{5}$. De esta forma, aunque se ponga en duda la viabilidad de la forma de tenencia de la tierra, ésta queda irremisiblemente asociada a la cosmovisión mexicana y a un tipo concreto de sistema de organización familiar.

\section{Características sociales en torno a la tenencia de la tierra}

El sistema familiar Mesoamericano constituye un patrón cultural de organización familiar y de parentesco muy antiguo, un testimonio vivo y dinámico de la civilización Mesoamericana (Robichaux, 2002, 2005). Numerosos estudios han estipulado un origen hispánico de determinados rasgos culturales, incluida la organización familiar y el sistema de ejidos, negando la pervivencia del patrón cultural Mesoamericano. Bonfil Batalla (1994) confronta la imposición del México Imaginario, al servicio de los intereses coloniales y con un notorio sesgo hacía el proyecto de occidentalización, sobre el México Profundo que encierra la realidad cultural y el origen Mesoamericano. Robichaux ${ }^{6}(2002,2005)$ propone conceptos alternativos para el estudio del "sistema familiar Mesoamericano", debido igualmente a la influencia occidental en los procedimientos teórico-

\footnotetext{
${ }^{5}$ Entendiendo el término Mesoamérica como un concepto construido sin límites territoriales y culturales bien definidos.

${ }^{6}$ Para Robichaux (2002) incluso los antropólogos con sus ideas sobre la familia y el parentesco han negado la existencia de la civilización mesoamericana.
} 
conceptuales en el estudio del parentesco. Sugiere un único patrón de reproducción social de la familia regido por un principio patrilineal. Los siguientes rasgos son indicadores que permiten reconocer un específico tipo de familia que corresponde a los grupos de Mesoamérica: residencia posmarital virilocal y gran número de familias extensas; transmisión por herencia de la casa paterna al varón ultimogénito que ejerce de cuidador de los padres ancianos; igualitarismo entre varones en la herencia de la tierra, aunque en muchos lugares la mujer no queda totalmente excluida; y, por último, la existencia de casas contiguas, generalmente encabezadas por varones emparentados por el lazo patrilineal (Robichaux, 2002). La reproducción endogámica, basada en la búsqueda de esposa dentro del ejido o la comunidad, todavía sigue presente, aunque no exenta de críticas. Por ello, es frecuente encontrar ejidos 0 comunidades en los que uno o dos apellidos se repiten insistentemente en la casi totalidad de las familias.

La familia extensa vive muy cerca debido a factores económicos, como la escasez de tierras, de herramientas agrícolas, falta de recursos para cubrir necesidades básicas, necesidades de mano de obra, colaboración en las tareas domésticas, etc. Las normas de residencia no son rígidas, también hay familias nucleares, pero cuanto mayor sea un grupo familiar mayor es la fuerza de trabajo disponible. La familia extensa representa seguridad para sus miembros y para la comunidad, proporciona mejores herramientas para la concentración de unos recursos naturales y humanos que son limitados y para evitar la fragmentación social (Jiménez Castillo, 1985).

Sobre los lazos de parentesco tienen lugar numerosas alianzas entre líderes o facciones políticas, lo que constituye un mecanismo de selección para el reclutamiento de clientela política. Los vínculos familiares pueden convertirse, de esta forma, en lazos políticos en torno a los intereses de un grupo de poder. La familia es un factor importante para conformar los grupos de poder, pero no es determinante, ya que el parentesco puede ser rebasado por intereses orientados hacia fines políticos o económicos (Azaola Garrido y Krotz, 1976).

El sistema de compadrazgo amplía y consolida la red de relaciones sociales que se traduce en formas de ayuda mutua, intercambio de productos, fuentes informales de crédito y vínculos políticos. Los padres generalmente buscan padrinos para sus hijos en el bautizo, comunión, casamiento (Jiménez Castillo, M. 1985). Los lazos de compadrazgo dentro de la misma comunidad permiten un contacto más frecuente y por lo tanto se crean expectativas sobre mayor constancia en los vínculos de reciprocidad (Azaola Garrido y Krotz, 1976).

Para Jiménez Castillo el sistema hegemónico ha convertido la producción del campesinado y al medio donde lo produce (la tierra) en simples mercancías, lo que ha generado la estratificación de clases en el interior de la comunidad campesina. Esta situación ha obligado a modificar las relaciones sociales de producción y ha provocado conflictos dentro de su estructura interna. La lucha por el poder y por la posesión de los recursos naturales ha resquebrajado la concepción comunitaria girando hacia un tipo mercantil, especialmente en la articulación con la sociedad mestiza nacional. Por eso, tanto ejidatarios, comuneros y minifundistas participan en el mercado regional e internacional bajo la condición de clase subordinada y explotada (Jiménez Castillo, 1985). 


\subsection{Las relaciones de parentesco y las diferencias de acceso a recursos internos y externos en una comunidad campesina}

Según los organismos oficiales la población se divide en ejidatarios, que poseen la tierra y el poder de decisión; posesionarios, que tienen tierras, pero no son ejidatarios; y avecindados, pobladores migrados de otras localidades que no tienen tierras. Debido a la inestabilidad de dicha clasificación y a otras cuestiones prácticas se ha estructurado la población en grupo de liderazgo y grupo de dependencia. El grupo de liderazgo lo forman algunos descendientes del genograma 1 y tres familias más, unidas a ellos mediante matrimonio o compadrazgo.

El acceso a la tierra y a la vivienda, las actividades económicas y las redes de reciprocidad y ayuda mutua están directamente vinculados al grupo de filiación.

El siguiente genograma representa a la familia más influyente de la localidad, que además en un primer momento estableció relación familiar con los hacendados. Tres descendientes de los hacendados contrajeron matrimonio con tres descendientes de una familia local. Debido a la numerosa descendencia y al mayor número de varones, controlaron todas las decisiones desde el primer momento. Con un punto negro están señalados todos los ejidatarios, algunos de ellos fueron nombrados con siete años, contrariamente a la legalidad. Al resto de la población sólo se le permitió un ejidatario por familia e incluso algunas de ellas fueron excluidas.

Genograma 1

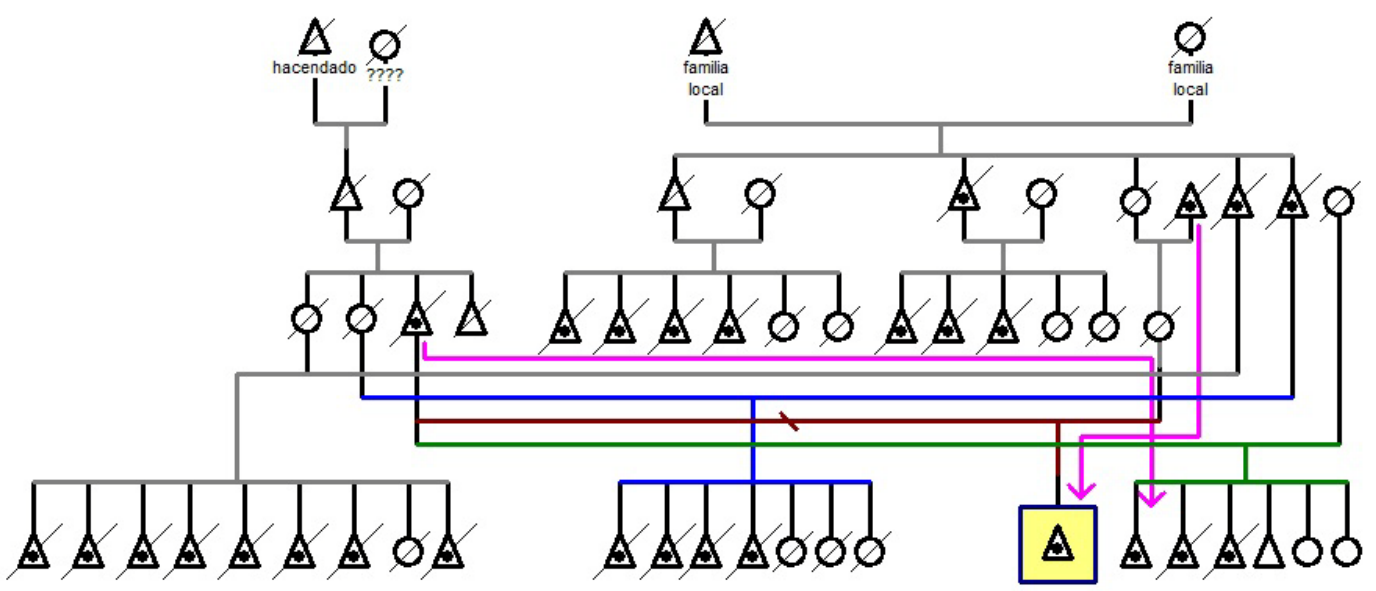

$\triangle \quad$ Ego $\rightarrow$ Herencia de ejidatario

A Ejidatario

El grupo de dependencia está formado por los exhacendados, el resto de nativos y los pobladores. Solamente a un varón por familia se le permitió ser 
ejidatario, excluyendo totalmente de la posibilidad a los avecindados 0 pobladores. El grupo de dependencia, a pesar de su heterogeneidad, presenta un factor común: la pugna por el acercamiento a la toma de decisiones, lo que implica el acceso a la tierra y a los recursos.

A pesar de que legalmente el título de ejidatario se hereda para siempre, ha habido numerosas irregularidades que han afectado a la situación del resto de familias de la localidad, tales como ventas de títulos e incluso retirada de los mismos, despojo de tierras y expulsiones de la comunidad. Todo ello debido a la oposición de algunas personas a la gestión interesada de los líderes.

En el genograma 2 podemos ver un ejemplo de ello. El título de ejidatario de la primera generación "desaparece" de la familia al fallecer el titular, siendo otorgado a un descendiente del genograma 1.

\section{Genograma 2}

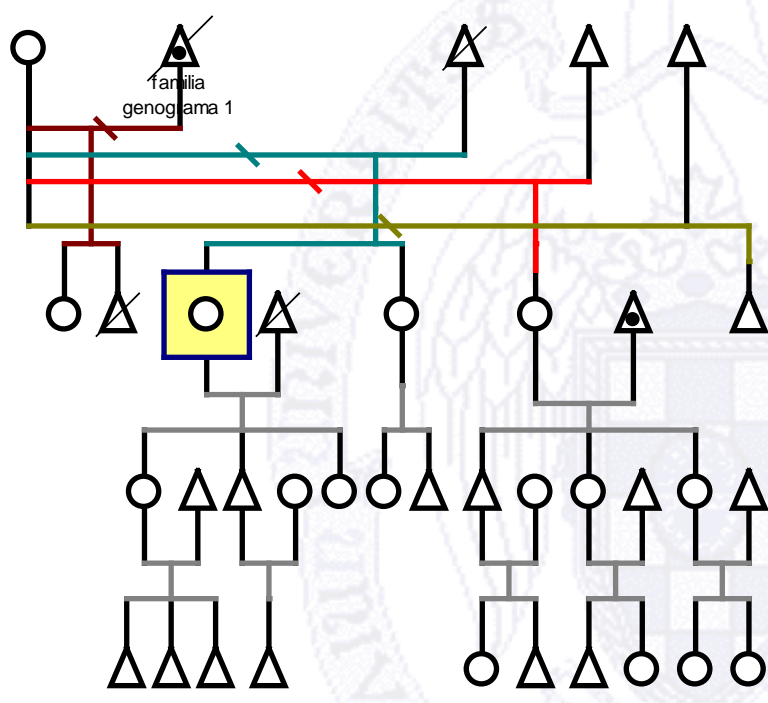

Los ejidatarios del genograma 1 han controlado todas las decisiones relativas al ejido. Antiguamente los cargos se decidían en asamblea y en votación pública. Con derecho a reelección o sin él, muchas personas de esta familia han desempeñado los mismos puestos durante cuarenta años, y actualmente los ocupan sus descendientes.

Las relaciones entre el grupo de liderazgo y el grupo de dependencia están condicionadas por las relaciones de parentesco y compadrazgo. Los líderes apoyan en momentos puntuales a sus familiares del grupo de dependencia, y como contraprestación éstos apoyan a los líderes en la toma de decisiones, manteniendo el sistema y perpetuando la desigualdad. Las situaciones de desigualdad social son especialmente visibles en las mujeres, ya que han estado prácticamente excluidas del acceso a la toma de decisiones, así como de la tierra y la vivienda, lo que implica también la casi imposibilidad de conseguir subsidios de gobierno mediante los proyectos para el desarrollo rural. 


\subsection{Proyectos para el desarrollo rural desde una perspectiva cualitativa}

Los gobiernos federal y estatal ofrecen a los individuos y grupos la posibilidad de solicitar subsidios para diversas actividades económicas, generalmente agropecuarias, comerciales o artesanales. Pero para solicitar un proyecto se necesita un capital previo que, en numerosas ocasiones, es entregado a los actores involucrados en la admisión de solicitudes, alimentando de esta forma las redes clientelares. Rastrear los procesos mediante los cuales se obtienen los subsidios de proyectos es un arduo y complejo trabajo, ya que de ellos se benefician los grupos de poder locales, excluyendo al resto de la sociedad, y ocultando en la medida de lo posible la información al respecto. Los proyectos pueden ser solicitados de forma individual o familiar, grupal como sociedades, o comunitarios con objetivos que beneficien a una localidad concreta. La finalidad de cada tipo de solicitudes no determina el éxito o fracaso de los proyectos. Es decir, los proyectos individuales o familiares tienen éxito porque el subsidio recibido es destinado a mejorar la economía doméstica; sin embargo, el capital recibido mediante los proyectos grupales y comunitarios puede beneficiar a la cooperativa o a la comunidad, pero también enriquecer al grupo que lidera su gestión.

Los subsidios de proyectos y programas, en algunas zonas, se han incorporado como mecanismo tradicional de financiamiento familiar. La figura 1 , construida mediante investigación cualitativa, muestra el esquema de la economía de supervivencia campesina. El valor es meramente ilustrativo, pero indicativo de la dependencia de los subsidios. Pero el subsidio a pequeños productores es cuantitativamente menor que el que reciben los intermediarios financieros, especialmente los bancos (Deugd, Villalobos, Vuskovic; 2006).

Figura 1

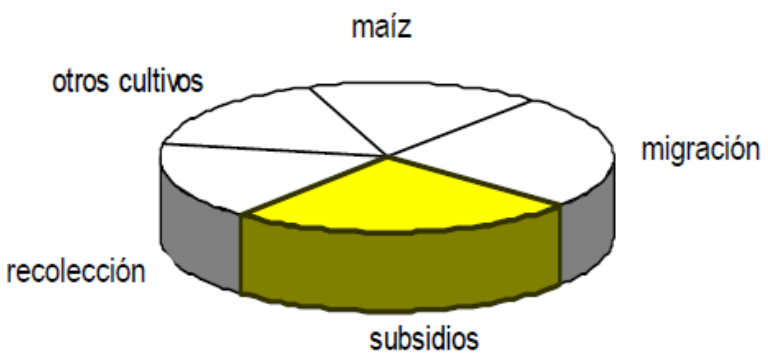

Fuente: Deugd, Villalobos, Vuskovic; 2006: 31

Las limitaciones para solicitar un crédito en el mundo rural han sido analizadas por numerosos autores:

La falta de garantías al solicitar un crédito, la poca información donde recurrir a solicitarlo y las diferentes formas de exclusión a los servicios financieros, coloca a las personas que pertenecen al sector rural como los más vulnerables 
para acceder a estos servicios (Almeraya Quintero, Figueroa Sandoval y otros, 2011) ${ }^{7}$.

Pero no sólo los bancos ejercen de intermediarios. Para solicitar un proyecto es necesario poseer los contactos adecuados, partiendo de las personas que conocen el procedimiento y la capacidad para diseñar la propuesta. Este intermediario recibirá al menos un $10 \%$ de lo que el campesino obtenga de subvención, aunque el propietario de una empresa de almacenamiento y distribución de un producto relató cómo le habían ofrecido presentar un proyecto, con la seguridad de su aprobación, al que debía de contribuir con un $83 \%$ de lo obtenido ${ }^{8}$. Por otro lado, es necesario poseer un capital previo considerable, puesto que las obras deben de estar comenzadas antes de la concesión del subsidio, es decir, cuando se realice la inspección. Estas condiciones excluyen a los más necesitados de la posibilidad de solicitar un recurso, ya que ni poseen capital ni redes clientelares apropiadas para ello.

La perspectiva cualitativa aporta numerosos ejemplos que corroboran la perpetuación de desigualdad y la reproducción social. Veamos algunos de ellos.

A mediados del siglo XX el Estado de Veracruz necesitó otorgar créditos y formar a técnicos para que enseñaran a los cafeticultores a aumentar la producción que demandaba el mercado internacional, así como las técnicas de procesamiento del café. En un principio los beneficios repercutieron exclusivamente en los grandes propietarios, pero con el tiempo se crearon cooperativas de campesinos en toda la región, y con el apoyo del instituto Mexicano del Café comenzaron a participar en el procesamiento y la comercialización (Córdoba Santamaría, 2009). No obstante los ejidatarios que lideraban las comunidades controlaron los recursos internos y externos. En la comunidad campesina de referencia los ejidatarios del grupo de liderazgo, construyeron por medio de proyectos un beneficio para procesar el café, una granja de cerdos y un almacén para el acopio y venta de limón que actualmente se exporta a Estados Unidos y Europa. El beneficio de café supuso importantes ingresos para toda la comunidad, sin embargo, las presiones del comercio internacional y la desaparición de las instituciones gubernamentales que apoyaban a los productores supuso el fracaso y cierre de las instalaciones en numerosas localidades de la región, incluida la comunidad que nos ocupa. El grupo constituido para el proyecto del café continúo con la granja de cerdos y posteriormente con la empacadora de limón, al mismo tiempo que el cultivo de café era sustituido progresivamente por el de limón. Con todo, la pésima gestión y la desaparición de importantes sumas de dinero por parte de los ejidatarios líderes llevaron al fracaso a las dos últimas empresas, que actualmente se encuentran rentadas.

Una última sociedad de importancia en la comunidad se formó con el objetivo de fomentar un turismo rural, cultural y en defensa de la naturaleza. En los últimos años han desviado la atención hacia la conservación de los espacios naturales como el cerro y la barranca, y aves protegidas como los tucanes, para lo que reciben sustanciosas cantidades de dinero. El grupo lo constituyen

\footnotetext{
${ }^{7}$ Artículo consultado en la web sin paginación.

${ }^{8}$ El proyecto se presentaría por un millón y medio de pesos mexicanos, pero el empresariocampesino recibiría tan solo doscientos cincuenta mil.
} 
unas treinta personas, líderes o familiares de ellos. La mayoría no son ejidatarios ni ejidatarias, ni poseen tierras en el cerro o en la barranca. El descontento generalizado del grupo de dependencia hacia esta asociación viene motivado por varios factores: la sociedad recibe subsidios para la conservación del medio ambiente en zonas comunes del ejido, pero no realiza ningún tipo de mantenimiento ni de control sobre la flora y la fauna local, permite que extranjeros y turistas esquilmen dichos recursos, y por último, no reciben subsidios los verdaderos propietarios de estas zonas comunes.

Las políticas públicas han contribuido necesariamente a la modificación de determinadas prácticas en las comunidades. En el Estado de Veracruz fue notable el apoyo que recibieron los campesinos, especialmente los líderes, para instalar beneficios de café, posteriormente se fomentó la transformación del cultivo hacia los cítricos y actualmente las políticas públicas pretenden favorecer a las asociaciones que fomenten el turismo. Estas transformaciones se ven igualmente influenciadas por la situación política y económica internacional y que, motivaron la segunda reforma agraria, conocida como PROCEDE, pero que nuevamente no ha repercutido positivamente en el campesinado humilde.

\section{EI PROCEDE y la influencia en los proyectos de desarrollo rural}

El Tratado de Libre Comercio y el Banco Mundial exigen el diseño de políticas neoliberales para aumentar la competitividad, fomentar la privatización y promover el individualismo ${ }^{9}$ como mecanismos para disminuir las desigualdades sociales en el sector rural. En México la mitad de la tierra es de carácter social y pertenece a ejidatarios y comunidades.

Para Quesnel y del Rey la ratificación del TLC en 1994 y las políticas públicas de los últimos veinte años han provocado una restructuración de los flujos de mano de obra procedente del ámbito rural e importantes procesos migratorios que se han desplazado de la Ciudad de México y las zonas petroleras hacia la frontera norte y hacia Estados unidos, con estancias más prolongadas. La nueva ley agraria ha ido acompañada de la reforma neoliberal agrícola que limita las subvenciones a los insumos y los productos agrícolas (Quesnel y Del Rey, 2005).

Según Yánez Naude, las reformas se han diseñado con el propósito de conducir al sector agropecuario hacia un contexto de economía de mercado, mediante la creación de instituciones, políticas y programas públicos (Yáñez Naude, 2006). Es por ello que el gobierno, accediendo a las recomendaciones de los organismos neoliberales, elabora en 1992 una nueva ley agraria, creando los Tribunales Agrarios para la solución de conflictos y la Procuraduría Agraria, que por medio del PROCEDE (Programa de Certificación de Derechos Agrarios y Titulación de Solares Urbanos), iniciado en 1993, pretende otorgar

\footnotetext{
${ }^{94}$ Las reformas individualizaron el crédito y eliminaron la mayoría de las funciones colectivas del ejido como unidad de producción y organización: contratación de crédito, comercialización de los productos, compra de insumos y maquinaria, industrialización, distribución, asistencia técnica, reparación de maquinarias, etc." (De Ita, 2003: 10).
} 
garantía jurídica a los ejidatarios respecto a la tenencia de la tierra, mediante la entrega de certificados parcelarios que garanticen la propiedad individual.

Sin embargo, la modificación del artículo 27 de la Ley de La Reforma Agraria de 1992 no pretende modernizar la legislación, sino adecuarla a los propósitos del gobierno respecto al campo. EI PROCEDE presenta dos modalidades a las que se puede acceder consecutivamente. La primera de ellas consiste en la medición de las parcelas, tal como se encuentran segregadas, y la entrega de certificados parcelarios a las personas que llevan un mínimo de cinco años trabajándolas. Esta primera opción supone cambios estructurales trascendentales: se limita la injerencia del Estado en los asuntos del ejido, por primera vez se reconocen los mismos derechos sobre las parcelas a posesionarios y avecindados $y$, por último, en esta fase, continúan sin obligaciones fiscales. Una vez obtenidos los certificados parcelarios el ejido puede mantenerse en esa situación o solicitar el dominio pleno, previo acuerdo en la asamblea de ejidatarios, obteniendo la propiedad privada individual, con todos sus derechos y obligaciones.

La nueva ley presenta dos ejes fundamentales: un conjunto de modificaciones en el sistema ejidal que, a largo plazo, contribuye a su desaparición; y un segundo eje que trata de garantizar la propiedad privada y su dirección hacia la mediana propiedad. Respecto a las modificaciones en el sistema ejidal, el Estado deja de actuar tutelarmente; autoriza las prácticas que ya venían realizándose al margen de la ley, como renta, aparcería y venta de derechos; permite que las parcelas sean garantía para los créditos; mayor elasticidad en cuanto a la creación de asociaciones entre ejidatarios y particulares; y por fin, se presenta la posibilidad de que el poseedor de la parcela asuma el dominio pleno (Morett Sánchez, 2008).

La solicitud de las mediciones de las parcelas y de los certificados parcelarios se establece con carácter voluntario, dependiendo del voto a favor de la mitad más uno de los ejidatarios en asamblea general. Pero para De Ita (2003) el PROCEDE fue inducido más que voluntario: es un requisito indispensable para acceder a otros programas gubernamentales; y para los ejidatarios y comuneros supone la legalización y el control sobre la tierra, proporcionando autonomía. No obstante, la densidad de la red de relaciones que las autoridades locales mantienen con las administraciones públicas y los organismos no gubernamentales determinan la eficiencia para captar y administrar programas y proyectos, así como la capacidad de orientación y mantenimiento de las familias que podrían o deberían ser excluidas ${ }^{10}$. Las relaciones entre las organizaciones y autoridades locales y los mercados políticos y económicos externos determinan el ingreso a programas y proyectos (Léonard, Quesnel y Del Rey, 2004).

En 2006 se preveía el cierre del PROCEDE, sin embargo los resultados no habían sido los esperados, por lo que el plazo se prolongó. A finales del año 2012 la casi la totalidad de los ejidos y comunidades habían solicitado la medición de las parcelas y los certificados parcelarios. La suma de la superficie

\footnotetext{
${ }^{10}$ Es el caso del Programa Oportunidades y las familias que reciben remesas que no declaran, o incluso cuando la madre-titular del programa ha emigrado a Estados Unidos. Las relaciones de parentesco y la afinidad con dichos organismos delimitan el acceso o la exclusión a una "bolsa local de recursos" (Léonard, Quesnel y Del Rey, 2004).
} 
parcelada y de dominio pleno suponen un $92,16 \%$, pero las diferencias entre una y otra modalidad son extremas. Apenas un $0,4 \%$ de la superficie parcelada ha sido transformada a dominio pleno.

Después de cien años con un modelo de tenencia de la tierra caracterizado por la falta de legislación y control interno, se presenta la posibilidad de medición y certificación parcelaria, la formalización de la propiedad y el reconocimiento de que, por fin, la tierra es de quien la ha trabajado durante los últimos cinco años, ya sean ejidatarios, posesionarios o avecindados. Estas parecen razones básicas para aceptar, al menos, la primera fase del PROCEDE. No obstante, el Estado libera el mercado de tierras y de trabajo agrícola, pero no ofrece soluciones a la inequidad en el reparto de la tierra, ni alternativas para optimizar el aprovechamiento de los recursos del país, así como tampoco la posibilidad de acceso a proyectos para el desarrollo rural de los más necesitados.

\subsection{Resultados del PROCEDE}

Según la Secretaría de la Reforma Agraria la mayoría de los ejidos que han solicitado el dominio pleno se encuentran en zonas periurbanas que intentan vender las parcelas a un precio más elevado (De Ita, 2003). Para el Banco Mundial la falta de interés por el dominio pleno se debe a que la propiedad ejidal está exenta de impuestos, mientras que la propiedad privada está obligada a cumplir con obligaciones fiscales. Para algunos autores (Morett Sánchez, 2008; De Ita, 2003) se debe a la asociación entre la tierra y la identidad y el espacio social que representa. No obstante, el modelo ejidal de tenencia de la tierra en México nunca constituyó una demanda en la Revolución, por el contrario, los indígenas y campesinos reclamaron la propiedad de la tierra. La entrega de certificados parcelarios no sólo supone mayor autonomía, sino el principal objetivo de la Revolución Mexicana.

Liberalizar el mercado de tierras no parece que solucione los problemas estructurales del campo mexicano, pero alivia las tensiones creadas durante cien años y permite un margen de maniobra a los campesinos.

Se ha criticado que muchos venden y otros compran demasiado, también que el reparto en la herencia fomenta aún más el minifundismo (Concheiro y Diego, 2001), situación que a priori parece que genere desigualdad. Desde hace décadas se viene denunciando que las dotaciones se han fragmentado de tal forma que no permiten a una familia subsistir con los productos del campo, a lo que se añaden los bajos precios de los mismos y el encarecimiento de los insumos. Entonces parece lógico y necesario que se dé una reestructuración en la propiedad de la tierra, y que continúen existiendo jornaleros agrícolas y empleados urbanos. Dónde no hay más tierra no puede haber más campesinos. No obstante, la venta de masiva de hectáreas se produce generalmente cuando la tierra no es apta para el cultivo o incluso por falta de infraestructuras para cultivar y trasladar los productos, ya que los campesinos no esperan que el gobierno realice las mejoras pertinentes para la obtención de un rendimiento óptimo de estas zonas. Es el caso de los cerros y las barrancas, terrenos que las multinacionales adquieren a muy bajo precio. También es frecuente que ejidatarios y posesionarios desconozcan los recursos minerales que albergan los cerros o sus posibilidades de explotación. Dos ejemplos tan 
sólo en la región de Xalapa ilustran la situación. En el municipio de Apazapan una cementera adquirió 400 hectáreas a muy bajo precio. Entre Alto Lucero y Actopan se encuentra la mina de oro Caballo Blanco, donde la compañía canadiense Goldgroup Mining Ing cuenta con los permisos necesarios para la extracción de oro. La mina se encuentra a 3 kilómetros de la Central Nuclear de Laguna Verde, en la costa del Golfo de México y los directivos del proyecto minero han reconocido públicamente la necesidad de utilizar explosivos ${ }^{11}$. Por otro lado la contaminación de los mantos acuíferos con cianuro podría afectar a veinte comunidades, que ya sufren escasez de agua ${ }^{12}$.

López Bárcenas y Eslava Galicia (2011) ofrecen una visión global de esta situación cuando afirman que durante el gobierno de Vicente Fox se entregaron 25 millones de hectáreas a empresas mineras y durante 4 años de la presidencia de Felipe Calderón casi 26 millones de hectáreas. Entre ambos han adjudicado aproximadamente 25.000 concesiones, es decir, el $26 \%$ del territorio continental mexicano.

La liberalización de la tierra con la aplicación del PROCEDE ha supuesto la mayor fuente de riqueza para políticos y compañías mineras, lo que demuestra que el objetivo fundamental de la reforma ha consistido en la privatización de la tierra para su posterior concentración en manos del capital privado, al mismo tiempo que políticos corruptos se enriquecían con ello. La última reforma agraria ha significado garantía sobre la propiedad de la tierra, pero sin más cambios estructurales se convierte en un beneficio simbólico, puesto que los niveles de pobreza en México han aumentado. Urdiqui señala algunos de los problemas que continúan sin solución: el rápido crecimiento de las ciudades las ha convertido en caóticas y sin servicios mínimos; la calidad de los servicios médicos y la falta de recursos destinados a las jubilaciones; grandes sectores de la población sin acceso a servicios médicos y hospitalarios; el deterioro en el medio ambiente y la calidad de vida a los que se une la violencia intrafamiliar 0 en las calles; el sistema educativo necesita nuevas visiones y métodos, especialmente por su relación con el deterioro de las condiciones sociales; y, por último, la población indígena de México representa el sector más aislado y discriminado en todos los ámbitos (Urdiqui, 1997).

La globalización de los mercados, la reorganización del sistema agroalimentario mundial y la flexibilización de los mercados laborales han generado una pluriactividad y movilidad poblacional de corte contemporáneo. Como consecuencia han surgido procesos de desagrarización, transformaciones en el uso de la tierra y mayor tasa de migración nacional e internacional. Los ingresos procedentes del sector agropecuario, que en el pasado fueron esenciales, se han convertido en complementarios, constituyendo el trabajo asalariado la principal fuente de ingresos familiares, junto con la producción artesanal y las actividades comerciales y de servicios. La desagrarización no implica la desaparición de las actividades agropecuarias, sino el aumento de ingresos de diversa procedencia (Salas Quintanal, Rivermar Pérez y Velasco Santos, 2011). Pero el PROCEDE también ha acelerado las transformaciones de las comunidades y ha generado incertidumbre. Se ha

\footnotetext{
${ }^{11}$ Información recogida en el diario "El Universal" el día 23 de febrero de 2012.

${ }^{12}$ Sobre el acceso al agua más información en ABOITES, L. (2009): La decadencia del agua de la nación. Estudio sobre desigualdad social y cambio político en México. Segunda mitad del siglo XX. El Colegio de México, México.
} 
finalizado el reparto agrario, así como la forma corporativa, la tenencia en usufructo y la intervención del Estado en los asuntos del ejido, pero sin embargo, nuevamente, no se interviene en la productividad ni en la modernización tecnológica. Por el contrario, el Estado ha reducido las subvenciones a proyectos e insumos, debilitando aún más a la clase campesina. Tampoco se insiste en la modernización ideológica, por lo que el ámbito rural y, especialmente, el indígena continúan asociándose en el imaginario mexicano a la marginalidad y la ignorancia. La liberación de la tierra ha permitido la explotación masiva de recursos naturales por multinacionales extranjeras y políticos locales y estatales corruptos. Las relaciones con el Estado y la Nación igualmente han sufrido modificaciones, dilatándose los beneficios económicos de las comunidades a partir de proyectos y programas gestionados por los gobiernos federal y estatal, si bien no se hallan exentos de complejidad.

\subsection{Proyectos: perspectiva cuantitativa}

Desde la Secretaría de Agricultura, Ganadería, Desarrollo Rural, Pesca y Alimentación (SAGARPA) se gestionan las subvenciones individuales y grupales para apoyar proyectos campesinos $e$ intentar reducir las desigualdades sociales, pero con resultados de dudosa calidad.

El análisis de los datos sobre proyectos aprobados durante los años 2009, 2010 y 2011, en la región de Coatepec arroja luz sobre las características de la población beneficiaria de este tipo de proyectos.

En SAGARPA, durante estos tres años se presentaron instancias para adquisición de plantas, sistema de riego, producción de anturio, invernaderos de anturios, equipo de bombeo, invernaderos de jitomate, construcción de galera agrícola, empacadoras de limón, etc. Las cuatro tablas que se presentan a continuación han sido elaboradas a partir de los datos proporcionados por SAGARPA en Xalapa, en la delegación perteneciente a la zona de Coatepec ${ }^{13}$ y corresponden a las localidades de Emiliano Zapata que han recibido subvenciones para proyectos.

Se ha separado en función del número de habitantes, ya que es un factor determinante en el número de proyectos solicitados y en las aportaciones de gobiernos y productor; de esta forma en primer lugar se encuentran las localidades de más 2.500 habitantes (en realidad solo son dos localidades que superan los 4.000 habitantes), en segundo lugar las comunidades entre $1.000 \mathrm{y}$ 2.499 y, por último entre 100 y 999 habitantes. Por otro lado, se han ordenado en función del grado de marginalidad señalado por la CONAPO, comenzando por los de grado muy bajo y como segundo criterio el número de habitantes. En la cuarta columna se señala la aportación que debe hacer el productor ${ }^{14}$, en la quinta columna la suma de la aportación comprometida por los gobiernos federal y estatal, acompañada en la siguiente columna por el porcentaje que representa $y$, por último, en la séptima columna la posición que ocupan en

\footnotetext{
${ }^{13}$ Las tablas proporcionadas presentan numerosos datos, aunque sólo se han extraído los considerados más relevantes para ofrecer una explicación concisa.

${ }^{14}$ Aunque en algunas ocasiones el productor también aporta mano de obra y materiales de la región no se han considerado porque el interés se centra en el esfuerzo en metálico que el productor debe realizar, y que además excluirá de la posibilidad de solicitar un proyecto a aquellas personas que no dispongan de un capital previo.
} 
función del dinero que reciben. La mayoría de las localidades debe aportar aproximadamente un 50\% del dinero necesario, pero podemos observar algunas excepciones.

Como aspecto coherente destacar que solamente hay tres localidades en las que la aportación comprometida de los gobiernos es inferior al $50 \%$ y corresponden a las localidades de La Estanzuela (48\%) El Lencero (44\%) y Buena Vista (48\%), siendo las tres consideradas por la CONAPO con grado de marginalidad bajo o muy bajo. En la situación contraria, es decir, las localidades con mayor aportación comprometida por los gobiernos (más del 70\%) y con marginalidad baja son El Chico (74\%), Cerro Gordo (72\%), El Aguaje (88\%) El Palmar (89\%) y, por último con marginalidad media Palo Gacho (84\%). Por lo que en lo referente al porcentaje recibido por el gobierno podemos afirmar, en el caso del municipio Emiliano Zapata, que varias localidades con marginalidad baja obtienen mayores apoyos que el resto. Confirmando esta situación El Carrizal (en la tabla 1) con grado de marginalidad muy bajo recibe también un $60 \%$.

En cuanto a la posición que ocupan en función del dinero que reciben podemos ver en la tabla 1 que a menor grado de marginalidad mayor es la aportación en metálico del gobierno. En la tabla 2, los dos primeros lugares son igualmente ocupados por localidades con menor nivel de marginalidad. El Terrero, con alta marginalidad se encuentra en la quinta posición, aunque como podemos ver recibe una cantidad muy inferior a las que reciben las dos primeras localidades.

En la tercera tabla podemos ver que las dos localidades con marginalidad baja ocupan las posiciones 1 y 4 , mientras que las localidades con marginalidad alta se encuentran en los lugares 7 y 9.

Tabla 1: población total mayor de 2.500 habitantes.

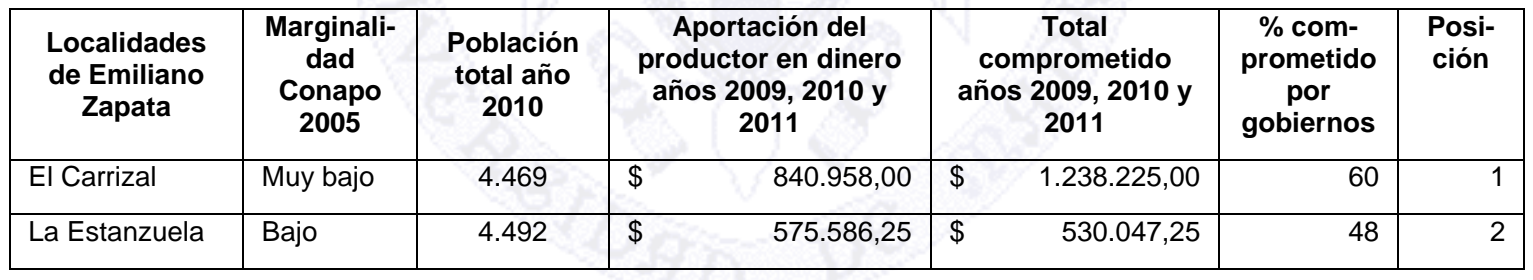

Tabla 2: población total entre 2.500 y 1.000 habitantes.

\begin{tabular}{|c|c|c|c|c|c|c|c|c|}
\hline $\begin{array}{c}\text { Localidades } \\
\text { de Emiliano } \\
\text { Zapata }\end{array}$ & $\begin{array}{l}\text { Marginali- } \\
\text { dad } \\
\text { Conapo } \\
2005\end{array}$ & $\begin{array}{l}\text { Población } \\
\text { total año } \\
2010\end{array}$ & & $\begin{array}{l}\text { rtación del } \\
\text { ductor en } \\
\text { años } 2009 \text {, } \\
10 \text { y } 2011\end{array}$ & & $\begin{array}{l}\text { Total } \\
\text { nprometido } \\
\text { s 2009, } 2010 \\
\text { y } 2011\end{array}$ & $\begin{array}{c}\% \text { com- } \\
\text { prometido } \\
\text { por } \\
\text { gobiernos }\end{array}$ & $\begin{array}{l}\text { Posi- } \\
\text { ción }\end{array}$ \\
\hline El Lencero & Muy bajo & 1.887 & $\$$ & $830.378,58$ & $\$$ & $629.248,50$ & 44 & 2 \\
\hline Chavarrillo & Muy bajo & 1.409 & $\$$ & $2.578 .854,82$ & $\$$ & $5.311 .409,32$ & 68 & 1 \\
\hline El Chico & Bajo & 2.480 & $\$$ & $101.252,00$ & $\$$ & $281.753,00$ & 74 & 4 \\
\hline Miradores & Bajo & 1.936 & $\$$ & $262.000,00$ & $\$$ & $260.219,00$ & 50 & 8 \\
\hline Cerro Gordo & Bajo & 1.557 & $\$$ & $20.000,00$ & $\$$ & $50.000,00$ & 72 & 10 \\
\hline Dos Ríos & Bajo & 1.307 & $\$$ & $45.000,00$ & $\$$ & $45.000,00$ & 50 & 11 \\
\hline $\begin{array}{l}\text { Rancho } \\
\text { Viejo }\end{array}$ & Bajo & 1.078 & $\$$ & $203.195,00$ & $\$$ & $203.195,00$ & 50 & 9 \\
\hline
\end{tabular}




\begin{tabular}{|l|l|l|lr|lr|r|r|}
\hline $\begin{array}{l}\text { Pacho } \\
\text { Nuevo }\end{array}$ & Medio & 2.673 & $\$$ & $234.027,50$ & $\$$ & $260.794,50$ & 53 & 7 \\
\hline Palo Gacho & Medio & 1.378 & $\$$ & $90.000,00$ & $\$$ & $480.000,00$ & 84 & 3 \\
\hline Alborada & Medio & 1.362 & $\$$ & $174.465,00$ & $\$$ & $270.176,00$ & 61 & 6 \\
\hline El Terrero & Alto & 1.244 & $\$$ & $245.422,50$ & $\$$ & $274.241,50$ & 53 & 5 \\
\hline
\end{tabular}

Tabla 3: población total entre 1.000 y 100 habitantes.

\begin{tabular}{|c|c|c|c|c|c|c|c|c|}
\hline $\begin{array}{l}\text { Localidad } \\
\text { es de } \\
\text { Emiliano } \\
\text { Zapata }\end{array}$ & $\begin{array}{l}\text { Marginali } \\
\text {-dad } \\
\text { Conapo } \\
2005\end{array}$ & $\begin{array}{l}\text { Població } \\
\text { n total } \\
\text { año } 2010\end{array}$ & & $\begin{array}{l}\text { tación del } \\
\text { ductor en } \\
\text { ero años } \\
9,2010 \text { y } \\
2011\end{array}$ & & $\begin{array}{l}\text { Total } \\
\text { nprometido } \\
\text { ños } 2009 \text {, } \\
10 \text { y } 2011\end{array}$ & $\begin{array}{l}\% \text { com- } \\
\text { prometid } \\
\text { o por } \\
\text { gobierno } \\
\text { s }\end{array}$ & $\begin{array}{c}\text { Posi } \\
- \\
\text { ción }\end{array}$ \\
\hline $\begin{array}{l}\text { Buena } \\
\text { Vista }\end{array}$ & Bajo & 932 & $\$$ & $732.000,00$ & $\$$ & $455.250,00$ & 48 & 1 \\
\hline El Aguaje & Bajo & 704 & $\$$ & $1.100,00$ & $\$$ & $7.700,00$ & 88 & 10 \\
\hline $\begin{array}{l}\text { El Palmar } \\
\text { (Estación } \\
\text { el Palmar) }\end{array}$ & Bajo & 417 & $\$$ & $27.320,00$ & $\$$ & $210.290,00$ & 89 & 4 \\
\hline La Tinaja & Medio & 968 & $\$$ & $228.400,00$ & $\$$ & $398.800,00$ & 63 & 2 \\
\hline $\begin{array}{l}\text { Rancho } \\
\text { Nuevo }\end{array}$ & Medio & 496 & $\$$ & $206.010,00$ & $\$$ & $208.414,00$ & 50 & 5 \\
\hline $\begin{array}{l}\text { Marco } \\
\text { Antonio } \\
\text { Muñoz } \\
\text { (Nacaxtle) }\end{array}$ & Medio & 472 & & 350,00 & $\$$ & 350,00 & 50 & 12 \\
\hline $\begin{array}{l}\text { El } \\
\text { Guayabo }\end{array}$ & Medio & 431 & $\$$ & $172.545,00$ & $\$$ & $286.251,00$ & 62 & 3 \\
\hline El Limón & Medio & 317 & $\$$ & $122.087,50$ & $\$$ & $122.922,50$ & 50 & 8 \\
\hline $\begin{array}{l}\text { Loma de } \\
\text { Rogel }\end{array}$ & Medio & 200 & $\$$ & $3.087,50$ & $\$$ & $4.322,50$ & 58 & 11 \\
\hline Plan Chico & Medio & 166 & $\$$ & $113.333,00$ & $\$$ & $180.000,00$ & 61 & 6 \\
\hline $\begin{array}{l}\text { Paso } \\
\text { Ladrillo }\end{array}$ & Alto & 279 & $\$$ & $150.000,00$ & $\$$ & $150.000,00$ & 50 & 7 \\
\hline Roma & Alto & 180 & $\$$ & $77.572,50$ & $\$$ & $108.601,50$ & 58 & 9 \\
\hline
\end{tabular}

Fuente: elaboración propia a partir de datos de SAGARPA

Resumiendo, a mayor grado de marginalidad menor es la cantidad de apoyos recibidos, y viceversa, a menor grado de marginalidad mayores son las subvenciones de las instituciones destinadas a proyectos, por lo que los proyectos vienen a representar una recompensa económica para los que disfrutan de mejor posición social. Y por otro lado, en las poblaciones rurales, la exclusión se acrecienta en las mujeres, que apenas tienen acceso a la tierra o a vivienda propia. En los proyectos existe también un reflejo de esta situación. En la tabla 4 podemos ver que durante los años señalados un total de 567 varones accedieron a subvenciones para el desarrollo rural, frente a 188 mujeres, lo que representa un escaso $25 \%$. 
Tabla 4: participación de hombres y mujeres en proyectos

\begin{tabular}{|l|c|c|}
\hline & Total hombres & Total mujeres \\
\hline 2009 & 351 & 96 \\
\hline 2010 & 132 & 39 \\
\hline 2011 & 84 & 53 \\
\hline TOTAL & 567 & 188 \\
\hline PORCENTAJES & $75,10 \%$ & $24,90 \%$ \\
\hline
\end{tabular}

Fuente: elaboración propia a partir de datos de SAGARPA

La perspectiva cuantitativa sobre las subvenciones del Gobierno para fomentar el desarrollo rural ha permitido comprobar que los grupos de poder no sólo ven legitimada la situación de dominio frente a su propia comunidad, sino que también desde los organismos oficiales se favorece a dicho grupo. Se puede concluir entonces que los proyectos benefician fundamentalmente a las localidades con menor marginalidad y a un grupo de varones, que además poseen recursos y contactos suficientes para participar en este tipo de subvenciones, excluyendo de las posibilidades del desarrollo rural a las personas de escasos recursos.

La legitimidad de la riqueza puede ser etiquetada como recompensa por el esfuerzo y su contribución a la colectividad, o puede ser considerada como un abuso que se obtuvo mediante mecanismos inadecuados que lesionan los derechos de los demás (Reygadas, 2008). Por lo tanto la legitimidad de la riqueza y del poder viene determinada por factores materiales y simbólicos, que además se consolida con la obtención de subvenciones para el desarrollo rural.

Se ha apelado a la "cultura de la pobreza" para legitimar la desigualdad aduciendo que la miseria es el resultado de formas culturales ajenas al progreso, tendentes al alcoholismo, la ausencia de seriedad en el trabajo y la afición a la fiesta. Actualmente se emplean argumentos más elaborados, como que la diferencia en el capital humano proviene de la baja escolaridad de los pobres, razón por lo que consiguen trabajos con bajos ingresos. De esta forma las desigualdades sociales se naturalizan, entendiendo que los pobres son actores pasivos que merecen su pobreza por la desgana en el trabajo, mientras que los ricos se ven recompensados por sus esfuerzos (Reygadas, 2009). Para Mestries las divisiones políticas y los diferentes estilos de relación con el Estado han impedido la consolidación de los movimientos sociales rurales. Así mismo las estructuras verticales de organización han negado la diversidad social y cultural y la pluralidad política de las bases. Pese a todo, las organizaciones campesinas han recuperado dinamismo político y capacidad de acción, han utilizado formas de resistencia y de creatividad tecnológica, jurídica y organizativa (Mestries, 2009). Pero para ello se necesitan unas condiciones muy particulares que combinan el clientelismo político y las relaciones de parentesco. Las relaciones verticales entre las instituciones oficiales y los campesinos líderes mantienen a éstos en un escenario de subordinación respecto a los primeros, y esta estructura se repite entre el grupo que hemos 
denominado de liderazgo, respecto al grupo de dependencia. Éste último se verá en la obligación de apoyar a los líderes para no ser excluidos en las solicitudes de subvenciones para proyectos grupales. Los proyectos de gobierno para el desarrollo rural son un reflejo más de la naturalización de la desigualdad y la perpetuación de las relaciones de dominación-subordinación.

\section{Reflexiones finales}

En las secciones precedentes hemos analizado los objetivos y consecuencias de las dos reformas agrarias. Ambas se presentan estimuladas por la intensificación de las políticas de marco capitalista, en lugar de procurar una redistribución equitativa de la tierra. Las dos reformas agrarias repercuten negativamente para los campesinos. Resumidamente se exponen las consecuencias de la primera de ellas:

1) El gobierno elabora un modelo organizativo estricto para mantener el control económico y político sobre los campesinos, quedando éstos subordinados al Estado.

2) Los campesinos dependen de créditos del gobierno y fundamentalmente de usureros.

3) Se establece una relación de subordinación con el mercado capitalista.

4) Se fomenta el caciquismo desde las propias instituciones.

5) Se fortalece el sistema familiar en base a vínculos de parentesco, generando dependencia hacia los líderes ejidatarios que mantienen relaciones con el gobierno y las instituciones.

6) A partir del diferente acceso a los recursos y a la toma de decisiones se generan verdaderas clases sociales en el interior de las comunidades.

7) Los campesinos pueden verse despojados de sus tierras y del título de ejidatario por sus propios compañeros.

Ante esta situación, el gobierno propone una segunda reforma agraria de corte neoliberal, suponiendo que la liberalización de la tierra mejorará las condiciones del campesinado más pobre y permitirá el acceso a créditos. Las consecuencias igualmente han resultado nefastas para los campesinos más pobres y significativamente similares a la primera reforma agraria.

El primer punto señalado anteriormente se modifica estructuralmente: se relajan de forma sustancial las condiciones del modelo organizativo de la tenencia de la tierra y el Estado deja de actuar tutelarmente y de interferir en todo lo relativo a las comunidades. Sin embargo este asunto repercute seriamente en favor de las multinacionales y de gobiernos corruptos, quienes son responsables del despojo de tierras a los campesinos. Ni multinacionales ni gobiernos marcan límites a la contaminación del agua y la tierra, lo que supone una forma más de expulsión. Respecto al resto de cuestiones señaladas como consecuencias de la primera reforma agraria no existe apenas variación con la segunda reforma. Los campesinos continúan dependientes de usureros 0 
financieras que ofrecen créditos a muy altos intereses y la brecha de subordinación respecto al mercado capitalista se ha incrementado. Las características sociales y familiares en torno a la tenencia de la tierra favorecen la combinación entre clientelismo político, relaciones de parentesco y dependencia de las instituciones, lo que genera y mantiene estructuras de dominación.

Todo ello, condiciona el acceso a la tierra y a los proyectos para el desarrollo rural, lo que refuerza la reproducción social.

La falta de asesoramiento desde las instancias de gobierno para elaborar un proyecto, la necesidad de contar con un capital personal para la inversión y la desigual distribución de los subsidios, se convierten en los principales problemas que los campesinos deben sortear, pero que en realidad, deja a los menos favorecidos fuera del sistema de apoyos. Estos factores son consecuencia, tal como hemos analizado, de las reformas agrarias y contribuyen a la perpetuación y la naturalización de la desigualdad.

\section{Referencias bibliográficas}

Aboites, L. (1980): "Apuntes sobre los trabajadores agrícolas de Coatepec, Veracruz, 1920-1980". Trabajo sin publicar. Departamento de Antropología, Universidad Autónoma Metropolitana Iztapalapa, México.

Aboites, L. (2009): La decadencia del agua de la nación. Estudio sobre desigualdad social y cambio político en México. Segunda mitad del siglo XX. El Colegio de México, México.

Almeraya Quintero, S. X.; Figueroa Sandoval, B.; Díaz Puente, J. M.; Figueroa Rodríguez, K. A.; y Pérez Fernández, L. M.: "Uso del crédito: implicaciones para el desarrollo rural". Revista Mexicana de Ciencias Agrícolas, Vol. 2, N. 1, enero/febrero 2011

Txoco. http://www.scielo.org.mx/scielo.php?script=sci_arttext\&pid=S200709342011000100009

Arizpe, L.: "Una sociedad en movimiento" en Arizpe, L. (ed.) (1993): Antropología Breve de México. Academia de la Investigación Científica, Centro Regional de Investigaciones Multidisciplinarias y UNAM, México.

Azaola Garrido, E. y Krotz, E. (1976): Política y conflicto. Instituto Nacional de Antropología e Historia, México.

Bonfil Batalla, G. (1994): México profundo. Una civilización negada. Grijalbo, México.

Cárdenas, C.: "Algunos problemas actuales de la reforma agraria" en Stavenhagen, R.; Paz Sánchez, F; Cárdenas, C.; Bonilla, A. (1968): Neolatifundismo y explotación. De Emiliano Zapata a Ánderson Clayton \& Co. Nuestro Tiempo, México.

Concheiro, D. y Diego, R. (2001): Una perspectiva campesina del mercado de tierras ejidales. Siete estudios de caso. Juan Pablos y UNAM, México. 
Córdoba Santamaría, S.: "Constructores de la cultura cafetalera del siglo XX. Finqueros y ejidatarios, dos sectores antagónicos" en Espinoza Ortega, A.; Cervantes Escoso, F.; Espinosa Ayala, E. (ed.) (2009): Balance y perspectivas del campo mexicano: a más de una década del TLCAN y del movimiento zapatista. Tomo II. Globalización y respuestas locales de la agroindustria. Asociación Mexicana de Estudios Rurales, Juan Pablos editor, Universidad Autónoma del Estado de México y Consejo Nacional de Ciencia y Tecnología, México.

De Ita, A. (2003). México: Impactos del Procede en los conflictos agrarios y la concentración de la tierra. Centro de Estudios para el Cambio en el Campo Mexicano (CECCAM), México.

Deugd, M.; Villalobos, I.; Vuskovic, P. (2006): "Políticas Públicas y servicios financieros rurales en México". Fondo internacional de Desarrollo agrícolaFIDA, Unidad Regional de Asistencia Técnica-RUTA y Programa de Apoyo a los Servicios Financieros Rurales-SERFIRURAL, México. http://www.ruta.org:8180/xmlui/bitstream/handle/123456789/218/282.pdf?seque nce $=1$

Jiménez Castillo, M. (1985). Huancito. Organización y práctica política. INI, México.

Léonard, E.; Quesnel, A. y Del Rey, A. (2004): "De la comunidad territorial al archipiélago familiar. Movilidad, contractualización de las relaciones intergeneracionales y desarrollo local en el sur del Estado de Veracruz", Estudios Sociológicos, vol. XXII, nº 003, septiembre-diciembre 2004, El Colegio de México, México, pp. 557-589.

López Bárcenas, F.; Eslava Galicia, M. M. (2011): El mineral o la vida. La legislación minera en México. http://www.cdiflorycanto-oax.org/doc/mineria.pdf

Mestries, F.: "Los movimientos sociales rurales en la década de la alternancia o las esperanzas frustradas" en Mestries, F.; Pleyers, G.; Zermeño, S. (ed.) (2009): Los movimientos sociales: de lo local a lo global. Anthropos, Barcelona, Universidad Autónoma Metropolitana de Azcapotzalcos, México.

Morett Sánchez, J. C. (2008): Reforma Agraria: del latifundio al neoliberalismo. Universidad Autónoma de Chapingo y Plaza y Valdés, México

Quesnel, A. y Del Rey, A. (2005): "La construcción de una economía familiar de archipiélago. Movilidad y recomposición de las relaciones intergeneracionales en el medio rural mexicano", Estudios Demográficos y Urbanos, vol. XX nº 002 , mayo-agosto 2005, El Colegio de México, México, pp. 197-228.

Reygadas, L. (2008): "Distinción y reciprocidad. Notas para una antropología de la equidad". Nueva Antropología: Simbolismo, identidades y diferencias, vol. XXI, nº 69, México, pp. 9-31.

Reygadas, L.: "Equidad intercultural" en Aguilar, M. A.; Nivón, E.; Winocur, R. (ed.) (2009): Pensar lo contemporáneo: de la cultura situada a la convergencia tecnológica. Anthropos, Barcelona.

Robichaux, D.: "El sistema familiar mesoamericano: testigo de una civilización negada" en De la Peña, G.: Vázquez León, L. (ed.) (2002): La Antropología Sociocultural en el México del Milenio. Búsquedas, encuentros y transiciones. 
Instituto Nacional Indigenista, Consejo Nacional para la Cultura y las Artes y Fondo de Cultura Económica, México.

Robichaux, D.: "El parentesco y su estudio entre los pueblos mesoamericanos contemporáneos" en Romana Falcón (1977): El agrarismo en Veracruz. El Colegio de México, México. Instituto Nacional de Antropología e Historia, México.

Sánchez Gómez, R. C. (1979): El Lencero: historia de una hacienda mexicana. Tesis para la obtención del título de licenciado en Historia. Facultad de Historia, Universidad Veracruzana, Xalapa.

Salas Quintanal, H.; Rivermar Pérez, L.; Velasco Santos, P.: “Introducción: Espacio y comunidad en época de la globalización" en Salas Quintanal, H.; Rivermar Pérez, L.; Velasco Santos, P. (ed.) (2011): Nuevas ruralidades. Expresiones de la transformación social en México. Universidad Nacional Autónoma de México, Instituto de investigaciones Antropológicas, Juan Pablos editor, México.

Stavenhagen, R. (1968): "Aspectos sociales de la estructura agraria en México" en Stavenhagen, R.; Paz Sánchez, F; Cárdenas, C.; Bonilla, A. (1968): Neolatifundismo y explotación. De Emiliano Zapata a Ánderson Clayton \& Co. Nuestro Tiempo, México.

Tejera Gaona, H.: "La comunidad indígena y campesina de México" en Arizpe, L. (ed.) (1993): Antropología Breve de México. Academia de la Investigación Científica, Centro Regional de Investigaciones Multidisciplinarias y UNAM, México.

Torres Mejía, P. (1993): El México obrero industrial" en Arizpe, L. (ed.) (1993): Antropología Breve de México. Academia de la Investigación Científica, Centro Regional de Investigaciones Multidisciplinarias y UNAM, México.

Urdiqui, V. L. (1997): México en la globalización. Condiciones y requisitos de un desarrollo sustentable y equitativo. Informe de la sección mexicana del Club de Roma. Fondo de Cultura Económica, México.

Womack, J. (2008): Zapata y la Revolución Mexicana. Siglo XXI, México (1969).

Yáñez Naude, A.: "Liberalización y reformas al agro: lecciones de México". Economía Agraria y Recursos Naturales, Vol. 6, N. 12, 2006, pp. 47-67. http://recyt.fecyt.es/index.php/ECAGRN/article/view/14326/8947 